\title{
De la insolidaridad social, hacia la necesidad de globalizar la solidaridad
}

Cristina Rivera

Departamento de Economía UCA, San Salvador

a II Jornada de Reflexión Económica "Padre Francisco Javier Ibisate", representa un momento y un espacio para recordar con profundo cariño y admiración al padre Ibisate, por ser un vivo ejemplo de humanidad y profunda consistencia. Es, además, un espacio para reflexionar de manera crítica sobre el actual entorno económico mundial, en un contexto de crisis sistémica.

Por ello, en este comentario se trae a colación una postura sostenida por el padre Ibisatesobre nuestra realidad social en la fase actual del capitalismo; y su incidencia en la configuración de este "mosaico desintegrado". Para ello, entre varios escritos del economista, dos resultan claves para analizar su pensamiento y visión sobre nuestra realidad, así como su perspectiva de una posible transformación: "Cumbre mundial sobre el desarrollo social de 1995: La pobreza, el desempleo y la integración social"1 y "La estrecha ruta hacia la globalización de la solidaridad"2. Por otra parte, al plantear la visión del autor, también se pretende mostrar algunas nociones que contribuyan a visualizar algunas de las manifestaciones de la dimensión social y humana de la crisis actual.

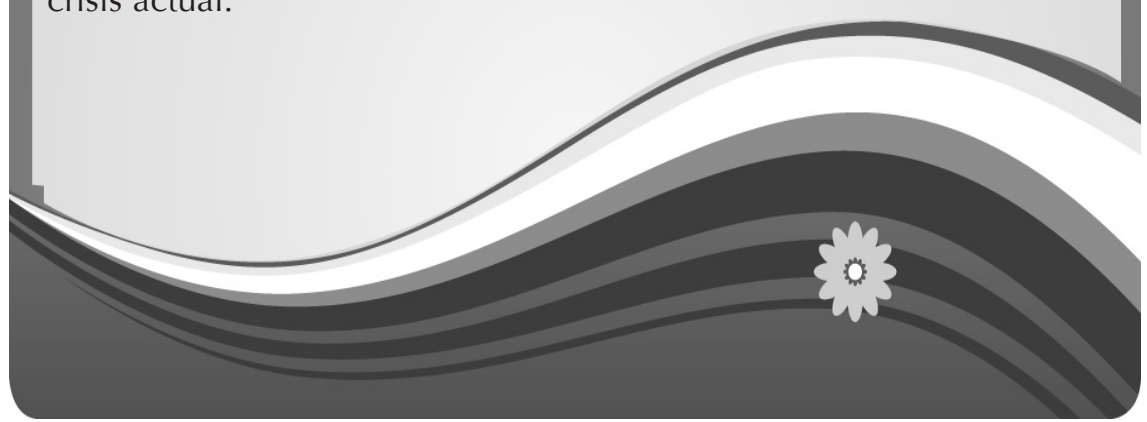




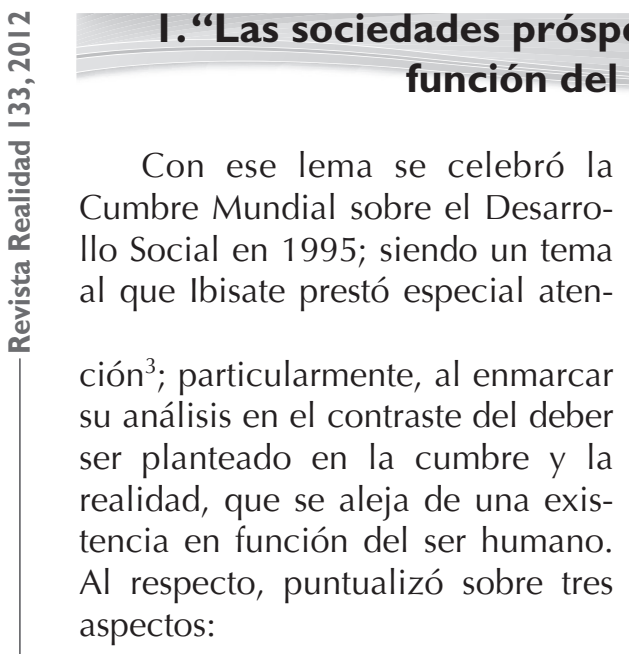

a. Disminuye el empleo productivo:

En su análisis multidimensional, el autor retoma el énfasis planteado por el Secretario General de las Naciones Unidas, al enmarcar el "problema del empleo en un entorno de crisis económica, crisis social y crisis moral, que termina en una gran crisis de incertidumbre" (1994: 851). Por ello enfatizaba que "la crisis del trabajo ha generado un 'colapso nervioso a nivel mundial', que se traduce en un extendido sentimiento de inseguridad, exclusión y desinterés social" (1994: 853).

b. La pobreza se ha generalizado:

Al respecto, Ibisate se pronunció afirmando que "progreso material y pobreza inimaginables coexisten mundialmente [...] al primero y segundo mundo se añaden el tercero y el cuarto porque la pobreza sigue ganando terreno" (1994: 848).
En el contexto de crisis actual, esta disparidad se acentúa, de ahí que nos encontremos con titulares como "Pobreza en EE.UU.: 'Mi mamá ha comido ratas'" ${ }^{\prime \prime}$, o "Las villas miseria de Estados Unidos, el país más rico del mundo" ${ }^{\prime 5}$; en ese sentido, cuando el padre Ibisateafirma que se trata de una pobreza que "es presente y tiene futuro" (1994: 849), encontramos en su pensamiento una comprensión de la pobreza en su dimensión social, enfatizando el desamparo que ésta implica, pues "'el pobre no es uno, es nadie; nadie por uno'. Es la mayor alienación y aislamiento" (1994: 850).

\section{c. Las sociedades se atomizan:}

Al referirse a la atomización social o insolidaridad social ${ }^{6}$, el economista enfatiza los elementos (1994: 842-844), que se presentan como los "síntomas de un mundo enfermo" o síntomas de desintegración social (1994: 857-859):

1. Los conflictos

2. La migración forzosa

3. Tráfico ilícito de drogas

4. Violencia doméstica

5. Disolución de los valores familiares

6. La corrupción

7. Centralización del poder político

8. Desaparición femenina

9. Discriminación y violencia

10. Discriminación racial 
11. Maltrato infantil

12. Turismo sexual infantil

13. Actividades ilícitas

14. Delitos

En este comentario se abordarán algunas de las ideas expresadas por el padre Ibisateal respecto de la atomización social o insolidaridad social y sus relaciones con las demás esferas, en tanto él se refiriera al "crecimiento con subdesarrollo", y nos hablase del "advenimiento de un mundo subdesarrollado" y de un "crecimiento con subdesarrollo humano" (1994: 844). Al identificar en su análisis el tema del crecimiento acompañado por la reversión del progreso en materia humana, y vincularlo a la insolidaridad social y a la disolución de los valores, lleva nuestra atención hacia la configuración de unas determinadas maneras de relacionarnos socialmente, que tienden a presentar como 'normales' la indiferencia ante el dolor y el sufrimiento de los seres humanos, y por ello se pregunta si "el crecimiento ise realiza a costa del subdesarrollo humano y ecológico?" (1994: 844).

\section{2. "El absurdo militarista"}

En vista del énfasis que nuestro autor realizaba respecto al tema de conflictividad, es retomado aquí en primera instancia; considerando además el papel clave que este "absurdo militarista" -como él lo calificó- (1994: 865), desempeña en el sostenimiento de la hegemonía estadounidense. Así, él afirmó que en la década de los noventa:

"Hemos pasado de una 'guerra-fría', a una 'paz-fría' [que es una] paz- violenta [...] las armas convencionales y las disuasivas son mortíferas en clave mayor: nos han habituado a contemplar con resignación -y a algunos con frialdad- las muertes masivas de inocentes, y también la lenta extinción de millones de personas [...] las guerras, la carrera armamentística y las luchas ideológicas nos han deshumanizado. Tal es la experiencia nacional donde encubrimos el informe de la verdad con la ley del olvido" (1994: 844-845).

Este absurdo implica que se utilice una "ética al revés" como instrumento de validación de la guerra, pues ésta se convierte en "el camino para la paz y la paz justifica cualquier guerra" (1994: 865). Así mismo, ejemplifica el subdesarrollo humano al que se ha referido, al derivar en una absoluta indiferencia ante el sufrimiento ajeno. Esta situación puede ejemplificarse con las invasiones estadounidenses en Iraq o Libia; o con las declaraciones del francotirador estadounidense 
Chris $\mathrm{Kyle}^{7}$ quien "dice que mató a 255 personas en Iraq y que no se

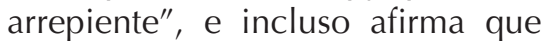
"me gustó lo que hice. Todavía me gusta". Tal como lo señalara el padre Ibisate, "acostumbrarse, por oficio, a matar conciudadanos, en virtud de órdenes recibidas y peor si es por un instinto adquirido, trasciende lo absurdo y se hunde en lo antihumano" (1994: 866).

Así mismo, este subdesarrollo humano es posible enmarcarlo en lo que el padre Ibisatei dentificó en $1982,{ }^{8}$ al afirmar que "si ha habido algún desarrollo ha sido sobre todo el "desarrollo de la amenaza y de la inseguridad", lo cual se ve sustentado en la "sSupercapacidad montada para la destrucción", cuyo calificativo encuentra su principal justificación más que en términos macroeconómicos, en términos de la capacidad de poner fin a miIlones de vidas, cegar el potencial humano y propiciar la indiferencia ante el dolor de nuestros pares.

Como pistas para identificar la magnitud de esta supercapacidad destructiva se dispone de la in- formación sobre las cien mayores compañías productoras de armas, entre las que se identifica una notable participación de las estadounidenses, con 47 empresas de dicho origen, cuya facturación por ventas de armas totalizó 275,910 millones de dólares; le siguen en importancia 11 compañías rusas 9 , lo que ubica a estos países como los principales exportadores de armas en el mundo; mientras que entre los principales importadores se encuentran India y China.

Adicionalmente, el 20 de marzo del corriente, ${ }^{10}$ aparece publicada la información sobre el mayor empleador del mundo: el Pntágono, con 3.2 millones de personas, seguido por el Ejército Popular de Liberación, en China, con 2.3 millones de personas.

En el cuadro 1 se muestra el gasto militar total de los doce países con mayor gasto en dicho rubro en el año 2011. Como puede observarse, la lista se encuentra encabezada por los cinco miembros permanentes del Consejo de Seguridad de las Naciones Unidas. 


\section{Cuadro 1. Países con mayor gasto militar total en 2011 En millones de dólares corrientes}

\begin{tabular}{lr}
\hline \multicolumn{1}{c}{ País } & \multicolumn{1}{c}{ Total } \\
\hline Estados Unidos & $711,421.00$ \\
China & $142,859.00$ \\
Rusia & $71,853.00$ \\
Reino Unido & $62,685.00$ \\
\hline Francia & $62,535.00$ \\
Japón & $59,327.00$ \\
India & $48,889.00$ \\
Arabia Saudita & $48,531.00$ \\
Alemania & $46,745.00$ \\
Brasil & $35,360.00$ \\
Italia & $34,501.00$ \\
Corea del Sur & $30,799.00$ \\
\hline
\end{tabular}

Fuente: SIPRI Military Expenditure Database 2011, http://milexdata.sipri.org

Es en vista de este comportamiento que el Padre Ibisate(2004: 1268) indicó que "se siguen levantando dos grandes obstáculos a la paz y a la seguridad del mundo: la estructura del Consejo de Seguridad y la negativa de las grandes potencias a ratificar los estatutos de la Corte Penal Internacional". Al momento de publicar el citado artículo "sólo noventa de los 191 países miembros [de la ONU] ratificaron los estatutos de la Corte Penal Internacional; EE.UU., Rusia y China, tres de los 5 Estados con poder de veto, no los han ratificado", ante ello se preguntaba "¿Cuál es la seguridad de los débiles y cuál es la solidaridad con el dolor del mundo" (2004: 1268). Ocho años después, son 121 de los 194 Estados miembros de la ONU los países que han ratificado dichos estatutos; entre ellos no se encuentran Estados Unidos, Rusia, China, ni El Salvador ${ }^{11}$.

Es de hacer notar que esta supercapacidad destructiva acumulada por los miembros permanentes del Consejo de Seguridad ocurre bajo amparo del tratado de no proliferación firmado en 1968, por el cual se conceden a sí mismos la autorización de producir y enriquecer uranio hasta el grado necesario para hacer una bomba. A la vez, es de dominio público que países no autorizados para tal producción (como Israel, Pakistán e India), están en posesión de este tipo de armamento, sin que por ello se hayan visto sujetos a sanciones por parte de la ONU.

Con su característica lucidez, el autor señaló y anticipó que son es- 
tos países, "los cinco miembros del Consejo de Seguridad [los que] desoyeron las voces de Boutros Ghali, cuando solicitó una policía internacional para detener las matanzas étnicas en Bosnia-Herzegovina, Ruanda, Sierra Leona, Timor y Zai- re; al mismo tiempo que una gran potencia, por decisión propia, había intervenido (y lo seguirá haciendo) en otros países" (2004: 1267); al respecto, resultan ejemplarizantes el caso de Libia y el actual escenario que está montándose sobre Siria.

\section{Los conflictos y la migración forzosa}

La concreción de ese "absurdo militarista" implica que el mundo se convierta en un espacio de conflictos y situaciones de violencia; tal como lo indicara nuestro autor, "la guerra revela la otra cara del neoliberalismo brutal e inaceptable" (2004: 1269).

El informe "¡Alerta 2012! Informe sobre conflictos, derechos humanos y construcción de paz" presentado en enero del presente por la Escola de Cultura de pau ${ }^{12}$, reporta que en 2011, se contabilizaron 40 contextos de conflicto armado, la mayoría en África (15) y Asia (12), seguidos por Oriente Medio (7), Europa (5) y América (1). Según los criterios proporcionados por el citado informe, se entiende por conflicto armado "todo enfrentamiento protagonizado por grupos armados regulares o irregulares con objetivos percibidos como incompatibles en el que el uso continuado y organizado de la violencia" que en el plazo de un año al menos produce 100 víctimas mortales " $y / o$ un grave impacto en el territorio (destrucción de infraestructuras o de la naturaleza) y la seguridad humana (ej. población herida o desplazada, violencia sexual, inseguridad alimentaria, impacto en la salud mental y en el tejido social o disrupción de los servicios básicos)"; y cuyos objetivos se diferencian claramente de las pretensiones de la delincuencia común y se orientan por ejemplo hacia demandas de autodeterminación, o hacia la oposición al sistema (político, económico, social o ideológico) de un Estado, o a la política interna o internacional, o hacia el control de los recursos o del territorio.

En este contexto, en el citado informe se reporta que de las 526,000 muertes anuales producidas a causa de acciones violentas letales, sólo una de cada 10 ocurría en contextos de conflicto armado o ataques terroristas ${ }^{13}$. Así mismo, se reporta que los países con una tasa promedio anual de más de 30 muertes violentas por cada 100,000 habitantes entre 2004 y 2009 eran: ${ }^{14}$ El Salvador, Iraq, Jamaica, Honduras, Colombia, Venezuela, Guatemala, Sudáfrica, Sri Lanka, Leshoto, República Centroafricana, Sudán, Belice y República Democrática 
del Congo; de los cuales únicamente Iraq, Colombia, Sri Lanka, República Centroafricana, Sudán y República Democrática del Congo se encontraban en el año 2009 bajo una situación de conflicto armado.

Esta conflictividad deriva en una siguiente manifestación del drama humano que representa la atomización social: la migración forzosa, pues "los conflictos también producen refugiados y migración forzosa; además de haberse convertido ésta en un negocio en sí misma" (1994: 843). Esta situación revela de forma particularmente grave los efectos del desarraigo y la disolución de las relaciones y vínculos socio-culturales en las sociedades; por ello, esta crisis humanitaria, tiene también una faceta cultural, pues implica la destrucción y el desarraigo de las personas desplazadas respecto a sus tradiciones y costumbres y a sus espacios socialmente edificados.

En el informe Alerta 2012! indica que en 2011 la población total refugiada en el mundo fue 15.4 millones de personas. Al respecto se indica una tendencia alcista en la población refugiada, comportamiento que también se registra en el número de personas desplazadas internas (que ascendió a $27.5 \mathrm{mi}-$ llones de personas), y se profundizó a lo largo del año. Algunos de los elementos que se encuentran a la base de estas situaciones están relacionados con el incremento en los precios de los alimentos, "el arrendamiento de grandes extensiones de tierra en países con serios déficits humanitarios a empresas y fondos de inversión extranjeros, así como el impacto de los conflictos armados en numerosos países del Cuerno de África" (ídem).

El desplazamiento forzado, que es también generado por la expulsión de la fuerza de trabajo en países como El Salvador, se agrava porque la migración se ha constituido en un negocio. Al respecto, un informe presentado por la Comisión Nacional de Derechos Humanos (México) ${ }^{15}$ en 2009, luego de recabar información durante seis meses, "el número de eventos de secuestro por año podría llegar a ser de alrededor de 400 y la cifra de víctimas podría ser de $18 \mathrm{mil}$ al año". De acuerdo a los datos presentados por dicho informe, el monto exigido a las víctimas en concepto de rescate oscila entre 1,500 a 5,000 dólares, siendo el promedio de 2,500 dólares por persona; de modo que los cálculos recopilados en el informe indican que "los secuestradores habrían obtenido un beneficio ilícito de aproximadamente 25 millones de dólares".

A esta problemática se agrega que "explotan los nacionalismos étnico-religiosos, la xenofobia, las avalanchas de emigrantes [...] las grandes naciones se encierran en la política del sálvese el que pueda" (1994: 845). 


\section{Comercio de drogas}

Entre las manifestaciones de la atomización social que ya se han indicado (el absurdo militarista - y el consiguiente comercio de armas-, los conflictos y las migraciones forzadas), se identifica una simbiosis con el comercio ilícito de drogas.

Ya en 1994 el Padre Ibisate señalaba que "tres grandes flujos de capitales alimentan tres Ilagas de la humanidad: el comercio de armas, el narcotráfico y el servicio de la deuda, amén de la corrupción que circula dentro de cada país"; por ello expresaba que la solidaridad no "encuentra su nido en los parámetros económicos del neoliberalismo triunfalista" (1994: 857).

En cuanto al narcotráfico, el economista afirmaba que "se con- sidera que los gastos de los EU en estupefacientes rebasan los ingresos (PIB) combinados de más de 80 países del mundo" (1994: 858).

Dannis Dayle, antiguo jefe de la élite de una unidad de cumplimiento de la $\mathrm{DEA}^{16}$, una referencia autorizada ilustra muy bien las dimensiones del problema al afirmar que "en mis treinta años de historia en la Administración para el cumplimiento de la ley antidroga y agencias relacionadas, los objetivos más importantes de mis investigaciones casi invariablemente resultaban estar trabajando para la CIA". De este modo se identifican claros vínculos entre el tráfico de drogas, y el despliegue militar; así lo ha referido Mantilla-Valbuena (2008: 239)

El tráfico de drogas y la inseguridad nacional o regional producidos por la violencia, la subversión y el terrorismo son pretextos para el despliegue estratégico-militar-policial de Estados Unidos en las Américas. El objetivo de este despliegue es ejercer control territorial, militar, económico, político y social en la cuenca andino-amazónica debido a los recursos naturales estratégicos que tiene: petróleo, oro, minerales diversos, piedras preciosas, maderas, plantas promisorias y animales exóticos, pero sobre todo agua dulce, oxígeno, biodiversidad genética y culturas ancestrales.

Tal como afirmó nuestro autor, citando a Vandana Shiva, "estamos pagando un alto precio en términos de democracia. Porque con su glo- balización consiguen como respuesta la violencia, y entonces necesitan estados policíacos para defender ese trato injusto" (2004: 1265). 
A pesar de este panorama, el padre Ibisate aún encontraba espa- cio para la esperanza, y consideraba que:

Este entorno mundial puede generar dos reacciones. La desilusión, el desánimo, la inclaustración, la teoría del fin del mundo. Este mismo cúmulo de datos que combinan la violencia con el sufrimiento, la riqueza y la pobreza, la maldad y la bondad, cataliza también la solidaridad con el sufrimiento, la pobreza y la bondad. Las antítesis pueden llevarnos a nuevas síntesis porque en el fondo somos seres humanos capaces de gestar un nuevo producto con toda esta aleación de luces y sombras (1994: 859).

En 1992 el padre Ibisate retoma de Adam Smith el convencimiento de que "ninguna sociedad puede ser floreciente y feliz, si la mayoría de sus miembros son pobres y miserables"17. Sin embargo, señala el agravante que representa el neoliberalismo pues "olvidando los 'sentimientos morales' de Adam Smith, impone las leyes del 'corazón invisible' a continentes sumergidos en la pobreza interna y en la deuda externa" (1994: 846-847).

Por ello, claramente para el padre Ibisatela respuesta debía provenir desde abajo, por lo que se refirió a una "cascada hacia arriba", pues "la solidaridad no puede venir desde arriba, como tampoco lo hace la 'fuente del derrame'" (1994: 869-870). Esta comprensión es vital, pues implica vislumbrar que un auténtico desarrollo requiere el reconocimiento de la otra persona en su calidad de ser humano con dignidad, y por tanto, implica rechazar el sufrimiento que se infringe a la mayoría de la población a través de la violencia física, económica y moral.

Desde la perspectiva del padre Ibisate, considerar la solidaridad como respuesta implica comprender que "la raíz última, el pecado original, hay que buscarlo en la ausencia de solidaridad" (1994: 847), pues el sistema económico vigente requiere el establecimiento de relaciones sociales de carácter insolidario que propicien la indiferencia entre los seres humanos y ante el sufrimiento del otro, a la vez que se potencia el individualismo, la búsqueda del lucro personal y los 'valores' de la 'empresa'. En vista de ello, se extiende en las personas el sentimiento de soledad y abandono, a la vez que se percibe la ausencia de libertad real y se dejan del lado los valores familiares y tradicionales que proporcionan la base de la unidad social. 
Por lo anterior, al insistir que "no hay economía sin satisfacción de las necesidades humanas fundamentales" (1994: 847), el autor reconoce que la economía no ha logrado resolver el problema eco- nómico de garantizar la existencia de las personas en condiciones que posibiliten efectivamente el despliegue de su potencial humano. Por ello, afirmó que:

"Frente a ese pillaje global surge un movimiento de recuperación de la globalidad de la humanidad y la tierra, en contra de la estrategia de acumulación de capital, que ha asumido, de forma ilegítima, el nombre de globalización. En vez de globalizar el mundo, lo destruye globalmente. [...] Se está transformando en el núcleo de una conciencia alternativa: un mejor mundo es posible. Hace ver que la misma globalidad de la tierra exige una alternativa" (Ibisate 2004: 1259).

En ese sentido, expuso la necesidad de que las sociedades compartan valores, matizando a su vez que "los valores del mercado no sirven para este propósito, porque sólo reflejan lo que un participante está dispuesto a pagar a otro, en un intercambio libre. Los mercados reducen todo, incluidos los seres humanos y la naturaleza, a mercancía" (2004: 1262). Tal como él lo señalara entonces "puede haber una economía de mercado, pero no una sociedad de mercado" (2004: 1262). Ante ello afirma que estos síntomas hacen urgente "concebir un nuevo ideal de progreso social basado en la responsabilidad, la libertad y la solidaridad" (1994: 844).

Por lo anterior, el padre Ibisate estaba convencido que la manera de resolver los problemas se encontraba en la cooperación: “¿Cómo resolver estos problemas globales [...]? Con la cooperación. No hay otra solución, porque nadie, ningún grupo, ningún país, ninguna institución dispone de medios y de la necesaria legitimidad para llevar a término, por sí misma esta tarea" (2004: 1273). Esto se comprende pues:

"Los 'modelos' económicos están hechos para 'remodelarse' de acuerdo al giro de la historia y a partir de la experiencia. Todo 'experimento' debe ser evaluado [...] Peor aún, si el modelo se impone para defender determinados intereses minoritarios con el envoltorio de democracia, libertad, progreso humano, justicia y paz social. Este parece ser el caso de la globalización neoliberal" (2004: 1261). 
De ahí la necesidad de una completa transformación de las relaciones sociales vigentes sustentadas en la explotación del ser humano y en la negación de su dignidad al ser tratado éste como una mercancía.
Tan especial como era el padre Ibisate, que, al encontrarnos trabajando algún sábado por la tarde, nos dijese: "vete a tu casa con tu familia; yo cuido el edificio", nos adelantó algunas palabras en nuestro desafío como Universidad:

A modo de médicos de la humanidad, porque las ciencias sociales son ciencias para los hombres, procuremos concretar las medicinas preventivas y curativas del subdesarrollo social. Primero, crear conciencia de estas realidades. Segundo [...] proponer alternativas realistas de desarrollo social, traduciendo en modelos y programas concretos las demandas que emanan de las mayorías populares. Quienes permanecemos en el rodaje continuo del ciclo tras ciclo tenemos este serio compromiso. Los desafíos son tecnológicos y nuestras ingenierías pueden abrir caminos en el área de la ciencia-tecnología. Los desafíos son económicos-empresariales, son jurídico-legales, son sociológico-grupales, son de incertidumbre-psicológica, son de educación-comunicación masiva, son filosóficos y son profundamente teológicos: en resumen son universitarios. Nuestra siembra de hoy es la cosecha del mañana y esta es la fe universitaria" (1994: 867-868).

\section{Bibliografía}

- Alexander, R. (2012) "¿Cuál es el empleador más grande del mundo?" en BBC Mundo [En línea] Disponible en http://www.bbc.co.uk/mundo/ noticias/2012/03/120320_empleador_mas_grande_mundo_adz.shtml

- BBC Mundo (2012) "Las villas miseria de Estados Unidos, el país más rico del mundo en BBC Mundo, 14 de febrero de 2012. [En línea] Disponible en http://www.bbc.co.uk/mundo/noticias/2012/02/120214_ eeuu_clase_media_campamentos_adz.shtml

- BBC Mundo (2012) "Pobreza en EE.UU.: "Mi mamá ha comido ratas"", en BBC Mundo, 14 de febrero de 2012. [En línea] Disponible en http:// www.bbc.co.uk/mundo/movil/noticias/2012/02/120214_video_eeuu_pobreza_az.shtml 
- Blum, W. (2004: 359) El Estado Agresor. La guerra de Washington contra el mundo, La esfera de los libros, Madrid.

- Comisión Nacional de Derechos Humanos (2009) Informe Especial de la Comisión Nacional de los Derechos Humanos Sobre los casos de Secuestro En Contra de Migrantes [En línea] Disponible en http://www.lawg.org/ storage/documents/informe\%20especial\%20de\%20la\%20comision\%20 nacional\%20de\%20los \%20derechos\%20humanos \%20sobre\%20los\%20 casos $\% 20$ de $\% 20$ secuestro $\% 20$ en $\% 20$ contra $\% 20$ de $\% 20$ migrantes $\% 20$ 09jun09.pdf

- Escola de Cultura de pau (2012). “¡Alerta 2012! Informe sobre conflictos, derechos humanos y construcción de paz"; Barcelona, Icaria editorial. [En línea] Disponible en: http://escolapau.uab.cat/index.php?option=com_content\&view $=$ article\&id=469\%3Aalerta-2012\&catid=61\&ltemid=89\&lang=es

- Ibisate, F. (1982) A propósito de "La crisis económica mundial" después de los setenta; en Boletín de Ciencias Económicas y Sociales, noviembrediciembre 1982, pp. 396-399.

(1994) "Cumbre mundial sobre el Desarrollo Social de 1995: la pobreza, el desempleo y la integración social" en Realidad, noviembre-diciembre 1994: 841-870

(2001) "Discurso del Padre Francisco Javier Ibisate S.J. (En agradecimiento por el Doctorado Honoris Causa otorgado por la UCA)" en Realidad, N 84, Noviembre-Diciembre 2001: 799- 806

(2004) "La estrecha ruta hacia la globalización de la solidaridad", en ECA Noviembre-diciembre 2004. 1257-1273.

(2008) Apuntes guías de Entorno económico mundial, 8085; UCA Editores, primera reimpresión.

(2008) Apuntes guías de historia económica, 195-200; UCA Editores, tercera reimpresión.

- International Criminal Court ICC http://www.icc-cpi.int/Menus/ASP/ states+parties/

- Mantilla-Valbuena, S. (2008) "Más allá del discurso hegemónico: narcotráfico, terrorismo y narcoterrorismo en la era del miedo y la inseguridad global" en Papel Político, Bogotá, Colombia, Vol. 13, No. 1, 227-259, enero-junio 2008.

- $\quad$ SIPRI (2011) "The SIPRI Top 100 arms-producing and military services companies, 2010" [En línea] disponible en: http://www.sipri.org/research/armaments/production/Top100.

- Uchoa, P. (2012) "Maté a 255 personas y no me arrepiento" en BBC Mundo, 15 de enero de 2012. 
1 Publicado en Realidad, noviembrediciembre 1994: 841-870

2 Publicado en ECA, noviembrediciembre 2004: 1257-1273

3 Algunos de los artículos y publicaciones en que se refiere a dicha temática son: "Cumbre mundial sobre el Desarrollo Social de 1995: la pobreza, el desempleo y la integración social", aparecido en Realidad, noviembre-diciembre 1994, pp. 841-870; Apuntes guías de historia económica, 2008: 195-200; Apuntes guías de Entorno económico mundial, 2008: 80-85; Discurso del Padre Francisco Javier Ibisate S.J. (En agradecimiento por el Doctorado Honoris Causa otorgado por la UCA) en Realidad, $\mathrm{N}^{\circ} 84$, Noviembre-Diciembre 2001.

4 BBC Mundo (2012) "Pobreza en EE.UU.: "Mi mamá ha comido ratas"”, en BBC Mundo, Martes, 14 de febrero de 2012.

5. BBC Mundo (2012) "Las villas miseria de Estados Unidos, el país más rico del mundo" en $B B C$ Mundo, Martes, 14 de febrero de 2012.

6 Discurso del Padre Francisco Javier Ibisate S.J. (En agradecimiento por el Doctorado Honoris Causa otorgado por la UCA) en Realidad, $\mathrm{N}^{\circ}$ 84, Noviembre-Diciembre 2001; asimismo, en La estrecha ruta hacia la globalización de la solidaridad (2004) indica que "Las sociedades prósperas son las que existen en función del ser bumano, contrastan la realidad de la globalización con el logo 'la pobreza se ha generalizado, disminuye el empleo productivo y crece la insolidaridad social; las sociedades se atomizan".
7 Uchoa, P. (2012) "Maté a 255 personas y no me arrepiento" en $B B C$ Mundo Domingo, 15 de enero de 2012.

8 A propósito de "La crisis económica mundial" después de los setenta; en Boletín de Ciencias Económicas y Sociales noviembre-diciembre 1982, pp. 396-399.

9 SIPRI (2011) “The SIPRI Top 100 arms-producing and military services companies, 2010”. Debe aclararse que en el informe se indica que podrían existir otras compañías rusas que deberían incluirse en la lista, pero para las que no hay suficiente información disponible. De igual manera, el informe aclara que no se han incluido compañías cuyas operaciones tengan su base en China.

10 Alexander, R. (2012) "¿Cuál es el empleador más grande del mundo?” en $B B C$ Mundo

11 International Criminal Court.

12 Escola de Cultura de pau (2012) “iAlerta 2012! Informe sobre conflictos, derechos humanos y construcción de paz”; Barcelona, Icaria editorial.

13 Según el informe: "La cifra de 526.000 muertes anuales es un promedio obtenido de balances de víctimas durante el periodo 20042009. Declaración de Ginebra sobre la Violencia Armada y el Desarrollo. Carga Global de la Violencia Armada: Encuentros Letales. Cambridge: Cambridge University Press, 2011.

14 El orden de los países se ha mantenido de acuerdo a lo presentado en el informe, mismo que indica que los datos se han retomado de la Decla- 


ración de Ginebra sobre la Violencia
Armada y el Desarrollo. Por su parte
el informe advierte que el dato “debe
ser relativizado dado que la distribu-
ción territorial de la violencia letal
dentro de un mismo Estado puede
variar según regiones, ciudades o
incluso barrios - segun las dinámicas
de los conflictos armados y de otros
factores detrás de la violencia, como
la criminalidad-y dada la dificultad
de obtener balances independientes
de víctimas mortales en conflictos
armados".

15 Informe especial de la Comisión Nacional de los Derechos Humanos sobre los casos de secuestro en contra de migrantes.

16 Citado en Blum, W. (2004: 359) El Estado agresor. La guerra de Washington contra el mundo.

17 Smith, A.; La teoría de los sentimientos morales; citado en Ibisate, F. (1992) "El Neoliberalismo no es un dogma de fe", en Realidad, septiembre-octubre 1992, 486. 